A nitrogen determination gave:

$$
\begin{aligned}
& \text { Calculated for } \\
& \mathrm{C}_{9 B} \mathrm{H}_{20} \mathrm{~N}_{2} \mathrm{~S} \text {. Found. } \\
& \text { Nitrogen............ } 7.16 \quad 6.90
\end{aligned}
$$

I wish to express my thanks to Prof. H. L. Wheeler for suggestions in carrying out this work.

\title{
THE DIRECT ESTIMATION OF FREE CARBONIC ACID IN NATURAL WATERS.
}

\author{
BY A. MCGILL, \\ Received December 7, 1903 .
}

FoLLOWING the valuable papers on this subject that have recently appeared in this Journal, ${ }^{1}$ the accompanying description of an apparatus which I have used for some time past, will probably be found interesting.

Much experience has convinced me that accurate knowledge of the amount of free carbonic acid (as distinguished from bound and half-bound) held in solution in deep well and spring waters, requires that the determination should be made at the source. No doubt it is possible by quite filling the container, by opening it only after thorough cooling, and by taking other precautions, to arrive at a very close approximation to the facts; but the observation of all the conditions of accuracy entails usually more labor than would the many times repeated determination at the source of supply. This latter affords the basis for a trustworthy average result, and with the apparatus about to be described, can be carried out quite satisfactorily.

The principles involved are simply the separation of the gas from the water holding it in solution, and the absorption of the liberated gas by appropriate solvents, properly standardized, and having automatic power of indicating the point of saturation.

The disengagement of the gas offers no difficulty. It is effected as in Drown's method, ${ }^{2}$ by aspirating (or forcing) air through the water. ${ }^{3}$ Instead, however, of merely driving off the free acid,

$1 \mathrm{~J}$. W. Ellms and J. C. Beneker: This Journal, 23, 405 (Igor); F. B. Forbes and G. H. Pratt: Jbid, 25, 742 (1903).

2 This Journal, 25,747 (1903).

${ }^{3}$ When air is bubbled through water containing alkaline or earthy bicarbonates in such dilute solutions as these occur in natural waters. there results no appreciable decomposition of such bicarbonates provided that the rate is not more rapid than 3 to 5 bubbles per second, or continued for more than an hour at the ordinary temperature. If, how- 
and estimating it by difference, I cause the displaced air to pass into a standard alkaline solution, where its absorption is effected. This necessitates that the carbon dioxide-free air be used in aspirating, a condition easily secured by the use of a soda-lime tube. At the same time, I arrange the rubber tube connections of the sample bottle, leaving them sufficiently long (eight to ten inches) to permit of shaking the bottle by hand from time to time. This bottle contains about an ounce of glass beads (solid) whose movement, on shaking the bottle, greatly facilitates the liberation of the acid from solutions. Complete absorption of the gas by the reagent, is a matter of greater difficulty; and I almost despaired of success, before I adopted the special absorption bottles of the following character.

The bottles are ordinary cylindrical phials 7 inches high, and $\mathrm{I} / 4$ inches in diameter. They are strong enough to stand the rough handling unavoidable in this kind of work. They are nearly filled with solid glass balls about $3 / 16$ to $1 / 4$ inch diameter. If these balls could be got of porcelain, or opaque white glass, it would greatly facilitate the readings. The inlet tube passes quite to the bottom of the bottle, and has its delivery end contracted to about $1 / 10$ inch. The outlet tube merely passes through the cork. Each bottle holds about $30 \mathrm{cc}$. of liquid in the interever, the air current be very rapid, bicarbonates give up more or less of their carbonic acid. The resultant monocatbonates react alkaline with phenolphthalein. In spite of their limited solubility, even calcium and barium monocarbonates give a recognizable pink tinge to the indicator named.

In order to prevent the possibility of confounding the "half bound" acid with the "free" acid sought, it is well to add phenolphthalein to the sample worked, when a pink tinge will indicate the point at which decomposition of bicarbonates begins.

The following experiments were made to determine the relative teadiness with wich bica rbonates of sodium, magnesium, calcium, and barium are decomposed under similat conditions by the action of a very rapid air current. In each case, 100 ec. of a solution containing the equivalent of 480 of calcium oxide per million as bicarbonate was used. The resulting liquid, alkaline to phenolphthalein, was titrated back till colorless with decinormal hydrochloric acid. The numbers quoted are cubic centimeters of tenth-normal acid required.

\begin{tabular}{|c|c|c|c|}
\hline $\begin{array}{l}\text { Bica rbonates } \\
\text { used. }\end{array}$ & $\begin{array}{l}\text { treatment. } \\
\text { rutes. }\end{array}$ & $\begin{array}{l}\text { cc. HCl tenth- } \\
\text { normal. }\end{array}$ & Rematbs, \\
\hline \multirow{2}{*}{ Sodium............. } & 10 & 0.4 & \multirow{2}{*}{ \} Solution clear } \\
\hline & 20 & 0.9 & \\
\hline \multirow{5}{*}{ Magnesium .......... } & 15 & 1.4 & \multirow{5}{*}{ Solution clear. } \\
\hline & 20 & I. 5 & \\
\hline & 25 & I. 7 & \\
\hline & 30 & 2.0 & \\
\hline & 60 & 3.1 & \\
\hline \multirow{2}{*}{ Calcium $\ldots \ldots \ldots \ldots$} & 20 & 0.1 & \multirow{3}{*}{$\begin{array}{l}\text { Solutionstutbid from mono- } \\
\text { carbonates Pink tint } \\
\text { quite distinct. }\end{array}$} \\
\hline & 30 & 0.1 & \\
\hline Batium $\cdots \cdots \cdots \cdots$ & $\begin{array}{l}10 \\
20\end{array}$ & $\begin{array}{l}0.1 \\
0.1\end{array}$ & \\
\hline
\end{tabular}


spaces among the balls. Once set up, these bottles are not taken apart for cleaning. They can be easily and thoroughly washed out by allowing carbonic acid-free water to run through them; and as readily emptied by forcing washed air through them in a reverse direction.

The absorbent solution is preferably barium hydroxide, N/IOO; but of course sodium carbonate may be used, if desired. I find the end-reaction decidedly sharper with the former; and, owing to the fact that one may use a considerable volume of the solution, the error due to atmospheric alteration becomes a negligible one.

I carry the standard solution in completely filled bottles of about $500 \mathrm{cc}$. capacity; and deliver the reagent by means of a pipette, (provided with a soda-lime guard tube) directly into the absorbers. The end of the pipette is introduced into the rubber tube attached to the end of the inlet tube, and any droplets remaining in this rubber tube are swept into the absorber by the current of aspirated air.

The estimation may be made on any reasonable volume of the water examined. I find $500 \mathrm{cc}$. a very practicable volume, but in cases where little carbonic acid is present in the free state, I use a liter; while quite often 200 or $250 \mathrm{cc}$. may be more suitable.

In a first experiment I begin by charging 3 or 4 absorbers with Io cc. of the reagent. I should say that this is already charged with phenolphthalein in sufficient amount to give a very decided coloration. The result of this trial experiment guides one in charging the absorbers for a second trial.

In order that complete absorption of gas may take place in each absorber of the series, care must be taken to pass the air bubbles not more frequently than 5 per second. At this rate, only negligible traces of carbon dioxide escape absorption; and the number of bottles which are decolorized gives an approximate measurement of the gas present in the volume of water operated on. Instead of using an aspirator in this work, I prefer to employ an India-rubber bag, about one quart capacity, provided with an outlet tube and stop-cock, and alsowith a valve such as is used on bicycle tires. An ordinary bicycle pump is used to inflate the bag, which can be blown up so as to deliver a gallon or more of air, under sufficient pressure to serve the purpose. Of course the advantage of this arrangement is merely its portability. 
It is evident that, by using a stronger standard solution (N/IO) in the absorbers, and by treating the sample with an acid, the totaI fixed carbonic acid can easily be determined, after the free acid has been expelled.

I have been very much pleased with the performance of the simple apparatus described, as I am sure any one will be who gives it a trial. Its obvious advantages are its simplicity, its portability, its permitting work to be done on comparatively large volumes of water, and its doing away with the need of carrying any measuring apparatus, other than a pipette, into the field.

Among other wits to which I have subjected it, I may say thit I have driven air for haif an heur through an aqueous solution of sot'um bicarbonate ( $1 \mathrm{gram}$ in $500 \mathrm{cc}$.) without lecolorizing $5 \mathrm{cc}$. $\mathrm{N}$ / Iobarium hydroxide (diluted with $20 \mathrm{cc}$. water) in the absorber. This of course merely served to prove the absence of free carbonic acicl in the water operated on. To the sample I. added $20 \mathrm{cc}$. sulphuric acid, passing the air through three absorbers containing respectively $25 \mathrm{cc}$, ro $\mathrm{cc}$, and $5 \mathrm{cc}$. of barium hrdroxide. In twenty minutes the first absorber was decolorizer ; in thirty minutes the second absorber, while the color had all but gone from the third. The air was passed at the rate of 3 to 5 bubbles per second.

\title{
DRY DEFECATION IN OPTICAL SUGAR ANALYSIS.
}

\author{
IBY W. IV. IIORSE.

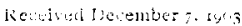

ThIE analysis of raw sugars, which is of so much importance both from the commercial and technical sides, naturally has received the closest attention by chemists, and the lnternational Commission for Uniform Methods of Sugar Analysis has done much to perfect the methods employed. The errors involved in polariscopic determination of sucrose have been gradually eliminated and several battles royal have been waged by the advocates of different ideas in arriving at the truth. Probably the most important error that remains and which has defied many earnest attempts to overcome it, is that due to the volume of the precipitate formed when clarifying the raw sugar solution with subacetate of lead to prepare it for observation in the polariscope. A year ago the writer devised a method for obviating, in great part, this error 